\title{
DA PAIXÃO PELA COZINHA À VISÃO EMPREENDEDORA: O CASO DA BARRACA DO CARIOCA
}

\author{
FROM THE PASSION BY THE COOKING TO THE ENTREPRENEURIAL VIEW: \\ THE CASE OF THE CARIOCA'S TENT
}

\author{
PATRINÊS APARECIDA FRANÇA ZONATTO \\ Professora da Universidade Franciscana (UFN) \\ Doutora em Administração - Universidade do Vale do Itajaí (UNIVALI) \\ E-mail: patrineszonatto@gmail.com / Orcid: http://orcid.org/0000-0002-7518-0590
}

Rua Professor Teixeira, 1284. Bloco B- Apto 306, Bairro: Nossa Senhora de Fátima - Santa Maria (RS).

AMANDA PATERNO SBISSA

Professora do Centro Universitário Uniavan

Doutoranda em Administração - Universidade do Vale do Itajaí (UNIVALI)

E-mail: amandapaternosbissa@gmail.com / Orcid: http://orcid.org/0000-0001-5588-4024

CARLOS RICARDO ROSSETTO

Professor na Universidade do Vale do Itajaí (UNIVALI)

Doutor em Engenharia de Produção - Universidade Federal de Santa Catarina (UFSC)

E-mail: rossetto@univali.br / Orcid: http://orcid.org/0000-0002-0718-4362

\section{VINÍCIUS COSTA DA SILVA ZONATTO}

Professor na Universidade Federal de Santa Maria (UFSM)

Pós Doutor em Ciências Contábeis- Universidade do Vale do Rio dos Sinos (UNISINOS)

Doutor em Ciências Contábeis e Administração - Universidade Regional de Blumenau (FURB)

E-mail: viniciuszonatto@gmail.com / Orcid: http://orcid.org/0000-0003-0823-6774

\begin{abstract}
RESUMO
Este caso para ensino tem como objetivo analisar como as competências empreendedoras podem contribuir para o crescimento e desenvolvimento da Barraca de cachorro quente do Carioca, para que a mesma não encerre suas atividades. A empresa está passando por sérios desafios financeiros e cada vez está mais difícil conseguir permanecer atuando neste ramo. Guiado pela necessidade e pela paixão por cozinhar, o proprietário Carioca como é conhecido, decidiu abrir uma pequena barraca no mesmo terreno de sua casa, para vender lanches e bebidas. No entanto suas vendas não estão como ele esperava, e Carioca se vê frente uma decisão difícil: Será que é hora de se reposicionar no mercado? O caso para ensino pode ser utilizado como material didático em cursos de graduação e de pós-graduação em administração e áreas afins. A elaboração do texto seguiu uma metodologia apropriada para caso para ensino. O caso possibilita ao professor explorar temas como, competências empreendedoras, tomada de decisão e a importância de um plano de negócios na constituição de uma empresa. Após análise da situação apresentada, os alunos são convidados a discutir sobre as competências empreendedoras, propondo soluções eficazes para a tomada de decisão. O caso é finalizado com notas de ensino e sugestões de aplicação em aula.
\end{abstract}

Palavras-chave: Plano de negócios; Empreendedorismo; Tomada de decisão .

Data de submissão: 31/05/2018. Data de aceite: 05/04/2019. Data de publicação: 13/08/2019. 


\begin{abstract}
This case study aims to analyze how the entrepreneurial skills can contribute to the growth and development of the Carioca hot dog tent, so that it does not end its activities. The company is facing serious financial challenges and it is increasingly difficult to remain active in this field. Guided by the need and passion for cooking, the owner Carioca, as he is known, decided to open a small tent in the same grounds of his house, to sell snacks and drinks. However, his sales are not as he expected, and Carioca faces a difficult decision: Is it time to reposition itself in the market? The case for teaching can be used as didactic material in undergraduate and postgraduate courses in administration and related areas. The elaboration of the text followed an appropriate methodology for case for teaching. The case enables the teacher to explore topics such as entrepreneurial skills, decision making and the importance of a business plan in the formation of a company. After analyzing the presented situation, the students are invited to discuss about the entrepreneurial skills, proposing effective solutions for the decision making. The case is finished with teaching notes and suggestions for application in class.
\end{abstract}

Keywords: Business plan; Entrepreneurship; Decision making.

\title{
CONTEXTO DO CASO
}

Naquele mês chuvoso de abril de 2013, Sr. Antônio, mais conhecido como Carioca, sua esposa Marta e sua filha Manuela resolveram mudar do Estado do Rio de Janeiro para o Estado de Santa Catarina. Cansado da cidade grande, com altos riscos de violência e, sem ser reconhecido pelo seu talento, sentia no peito uma vontade muito forte de buscar uma vida nova junto com sua família.

Carioca, então se mudou com sua família para a capital catarinense, Florianópolis, ao chegar na cidade, foi convidado para trabalhar na empresa de seu irmão, desenvolvendo trabalhos de locução, apesar de aceitar o serviço, Carioca permanece com seu coração inquieto, pois o desejo de abrir seu próprio negócio não sai da sua cabeça.

Após a instalação da família em Florianópolis, todos estavam com muito entusiasmo e otimismo, pois Carioca estava cheio de planos e queria colocar tudo em prática, rapidamente. Sua esposa Marta, o apoiava muito. Ela também estava animada e logo começou a trabalhar como cabeleireira. Como Marta já possuía um pequeno salão de beleza na cidade do Rio de Janeiro, logo conseguiu atuar no ramo indo trabalhar em um salão de beleza da região em São José, município vizinho a Florianópolis. A filha Manuela estava encantada com as belezas da região e rapidamente fez amigos no colégio. Tudo estava indo bem como haviam planejado e estavam confiantes com a nova mudança. Como eram novos e muito sonhadores, Carioca e Marta tinham ambições e planejavam um futuro promissor para sua família.

Carioca trabalhava como locutor dentro de lojas dos mais variados segmentos, onde convidava os clientes para entrarem e conhecerem a parte interna das lojas, os produtos, as promoções, os preços e assim por diante, fazendo um merchandising para as empresas que o contratavam. Esta era a tarefa que Carioca exercia diariamente com muito humor e profissionalismo, e após um ano de muito trabalho com competência e dedicação, ele estava estabilizado profissionalmente.

No entanto, uma inquietação beirava os pensamentos de Carioca, o de abrir o seu próprio negócio, pois ele pensava que sua vida era atrair clientes para as lojas, mas que ele poderia investir o seu tempo, buscando clientes para seu próprio empreendimento. 
Com as vendas baixas, de maneira geral, no comércio da grande Florianópolis, os contratos de locutor foram diminuindo, e isso foi deixando Carioca muito preocupado, pois tinha despesas mensais que precisariam ser quitadas, como luz, água, aluguel, colégio da filha, entre outras. Da mesma forma que diminuíam as oportunidades de trabalho para Carioca, o movimento dos clientes no salão de beleza onde Marta trabalhava também teve uma queda significativa, reduzindo a carga horária de Marta e, consequentemente, seu salário.

Carioca pensava, que agora talvez fosse o momento de investir no seu sonho, o de trabalhar para conquistar seus próprios clientes. Apesar de muito dedicado, e capaz de assumir os riscos que um negócio pode representar, Carioca ainda não sabia qual seria sua área de atuação.

Diante deste cenário Carioca pensou: E agora? Logo veio à cabeça sua grande paixão em cozinhar, porque ele já tinha como hobby cozinhar para os amigos. A visão empreendedora e a paixão pela cozinha levaram Carioca a abrir seu novo negócio: $A$ Barraca de Cachorro Quente do Carioca.

\section{A CRIAÇÃO DA BARRACA DE CACHORRO QUENTE DO CARIOCA}

Depois de um dia de muito trabalho, como de costume, Carioca senta-se junto a Marta para assistir televisão. Carioca e Marta começaram a falar da apreensão de verem as contas baterem na porta e o salário de ambos reduzirem. Neste momento Carioca sugeriu a Marta que mudassem para uma cidade vizinha a Florianópolis para reduzir as despesas mensais e falou do desejo de transformar seu hobby em uma atividade financeira para ajudar nas despesas da família.

No mesmo instante Marta achou uma ideia interessante e apoiou seu marido. Então começaram a procura por uma nova moradia em cidades vizinhas a Florianópolis. Ambos pensavam que em residir numa cidade menor, o aluguel e o custo de vida, de forma geral, seriam mais baratos. No entanto, talvez as oportunidades pudessem ser mais restritas, em função do potencial de consumo deste local. Assim, era necessário identificar algo que pudesse viabilizar a necessidade de reduzir estes custos e ao mesmo tempo viabilizar a possibilidade de abrir o próprio negócio.

Foi então que tiveram uma grande surpresa. Carioca e Marta encontraram uma casa que estava à venda por um valor muito acessível e ainda em um lugar privilegiado, ao lado de uma Universidade. Com o dinheiro que eles tinham guardado da venda da casa do Rio de Janeiro efetuaram a compra da nova casa, com um terreno amplo e uma boa localização. Logo, Carioca pensou que era viável morar naquele local e instalar seu negócio em frente à nova moradia da família.

No mesmo mês, mudaram para a nova casa, em uma cidade acolhedora de apenas sessenta mil habitantes. Uma nova vida se iniciava naquele momento. Carioca começou suas atividades fazendo cachorro quente para vender. Marta por sua vez, como havia aprendido muito nos salões de beleza em que havia trabalhado anteriormente, logo conseguiu trabalhar em um salão próximo a sua residência, e nas horas vagas e a noite ajudava Carioca em seu empreendimento.

Como a residência era pequena e a atividade alimentícia demandava cuidados especiais relacionados ao manuseio dos alimentos, higiene e limpeza, Carioca fez uma pequena estrutura de madeira em formato de uma Barraca em frente a sua residência para vender então seus lanches e bebidas. Dentre esses lanches está o produto principal o famoso 
cachorro quente, que era o produto mais procurado na barraca de Carioca pelos alunos da Universidade, seus principais clientes.

A Barraca era muito simples, mas o suficiente para atender bem seus clientes, um espaço pequeno, mas aconchegante. A estrutura inicial contava com apenas três mesas de plásticos, com três cadeiras cada uma para acomodar seus clientes, um freezer, um televisor e o fogão de chapa, e mais um balcão onde ficava o caixa. O diferencial estava no atendimento muito cordial prestado por Carioca, com o qual ele conquistava e fidelizava seus clientes. Em relação ao produto, seu principal diferencial era um crene de ervas finas, vendido junto com o cachorro quente, que alavancava as vendas deste produto. Seu sabor era incomparável, diziam seus clientes.

No entanto, em nenhum momento Carioca pensou em elaborar um plano de negócio para verificar se alcançaria os resultados desejados com a abertura da barraca, nem ao menos sabia o que tratava e se realmente se fazia necessário.

\section{O ATENDIMENTO DO CARIOCA}

Após o término de um dia cansativo, Bruna e Joana voltavam pra casa, depois de mais uma noite de estudos da universidade. As colegas são novas na cidade e residem em um apartamento próximo a instituição de ensino. No caminho para a casa as alunas encontraram a Barraca de Cachorro Quente do Carioca e ali estava atendendo um senhor muito simpático que imediatamente abriu um sorriso enorme ao vê-las, rapidamente surgiu a ideia de conhecer e saborear o lanche do novo vizinho.

- Boa noite meninas, tudo bem com vocês? Sou o Carioca, aqui está nosso cardápio.

Passados alguns minutos, Carioca questionou:

- Já decidiram o que vocês vão pedir meninas?

Após visualizar o cardápio oferecido, Bruna e Joana logo respondem:

- Eu quero um xis-salada completo, diz Joana.

- E eu, um cachorro quente, completa Bruna.

Carioca pergunta:

- Com purê de batatas e com creme de ervas finas?

- Como assim Carioca? (Pergunta Joana) Purê de batatas no xis-salada? Creme de ervas finas?

Com bom humor, Carioca sorri e responde.

- É a especialidade da casa, o purê de batatas e o creme, na verdade é uma maionese de ervas finas. É uma invenção minha. Faço o purê e bolei a ideia da maionese de ervas que é um sucesso. É opcional, mas recomendo vocês provarem!

- Certo, vamos provar as invenções do Carioca! Responde Bruna.

A barraca do Carioca oferece diversos tipos de lanches, mas, o mais tradicional é o cachorro quente, os lanches são de excelente qualidade, preza pelo bom atendimento, limpeza do ambiente e o cuidado no preparo dos lanches.

Carioca trabalha sozinho, atende aos clientes, faz o lanche, faz a limpeza do local, faz compra com fornecedores, com exceção da tele entrega, que é realizada por um funcionário. Enquanto prepara os alimentos solicitados pelas novas clientes, Joana e Bruna, como alunas do curso de administração e boas observadoras, não hesitam em questionar Carioca sobre seu negócio.

- Carioca, como surgiu a ideia de abrir a barraca de cachorro quente? Pergunta Bruna. 
- Bem... sempre tive uma habilidade na cozinha e um espírito empreendedor que me motivava em um dia pensar em abrir meu próprio negócio. Como aqui onde eu moro, o terreno é grande, consegui montar minha barraca em frente à minha casa. Vejam, minha casa está nos fundos (Carioca aponta para os fundos do terreno) e minha barraca aqui bem na frente da rua com a iluminação e banner atraindo os clientes. Consegui realizar meu sonho, apesar da grande dificuldade que estou encontrando.

- Dificuldades? Mais quais dificuldades? Joana pergunta.

- Ah meninas, são tantas! Primeiramente, vejo que as vendas estão fracas, esperava muito mais clientela em virtude da proximidade com a Universidade. Olhem meninas, a Universidade está aqui do lado, passam tantos alunos por aqui, principalmente à noite, eu não consigo atrair esses alunos para o meu negócio. Sei que poderia lucrar muito mais, pois não tenho concorrente nas proximidades.

Procuro oferecer um produto de qualidade com um preço justo, para que meus clientes possam retornar. Hoje tenho mais venda pela tele entrega do que aqui, por isso aumentei o portfólio de produtos e estou sempre inovando, meus clientes são extremamente fiéis, quando vem uma vez, vem sempre, isso é a qualidade do meu produto e um segredinho... "a maionese de ervas finas e o purê que dão um toque especial no sabor". Estou com algumas ideias, vamos ver se vai dar certo.

No mesmo momento, Bruna pergunta sobre seus novos projetos.

- Carioca, quais são essas ideias?

- Estou pensando em vender minha casa. Minha ideia é comprar uma casa menor e com o restante do dinheiro comprar um trailler e vender lanches na rua, em outros lugares, se o cliente não vem até aqui, vou até o cliente... mas, é só uma ideia que precisa ainda amadurecer.

- Ah, quer montar um Food Truck? Interrompe Bruna.

- Exatamente, mas estou um pouco confuso. Não tenho certeza se é uma boa ideia, tenho que considerar que onde estou hoje não pago aluguel, a casa é minha, o negócio é meu e a Universidade está aqui bem pertinho de mim é só questão de chamar esse povo pra cá! Como não estou conseguindo dessa forma, tenho que buscar novas alternativas e essa foi uma delas que pensei.

Nesse momento, Carioca serve o pedido das colegas.

- Aqui estão os lanches, espero que gostem!

Após alguns minutos...

- Hummmm... está uma delícia! Diz Bruna. Além do purê que deu um toque especial.

- É... essa foi uma invenção minha, o segredo está guardado a sete chaves (risos).

Após se deliciar com os lanches, as duas amigas se despedem e voltam para casa, mas algo toca os pensamentos de Joana:

- Bruna, não entendo como a barraca do Carioca não cresce, não se desenvolve. Ele tem tudo para dar certo, um atendimento excelente, um lanche delicioso e uma cordialidade com o cliente que não tem igual! Temos que fazer algo para ajudar ele.

- Realmente Joana, nós como futuras administradoras temos a missão de ajudá-lo, mas como?

- Eis a questão Bruna! 


\section{A BUSCA DE NOVAS SOLUÇÕES}

Quais medidas Carioca deve adotar para aumentar as vendas? Carioca é otimista e está sempre perseguindo novas oportunidades. Apesar de possuir poucos recursos, a partir de suas ideias, consegue lidar com as incertezas e faz o negócio acontecer. Mesmo com as dificuldades que vem enfrentando com a barraca de cachorro quente, sua paixão pelo negócio fala mais alto. E é essa paixão que Carioca acredita que vai ajudá-lo a seguir em frente. No entanto, a dificuldade está em captar novos clientes para alavancar suas vendas e mesmo com muita determinação, criatividade e capacidade de enfrentar desafios diários, Carioca sabe que precisa criar oportunidades para sua pequena empresa.

Vender o terreno com a casa e comprar um trailler foi uma ideia que Carioca pensou, mais logo vem à sua cabeça várias perguntas, tais como: Quem garante que vai dar certo, onde vou posicionar o trailler para vender? E se eu sair da região onde estou instalado e ir para outro local, posso encontrar concorrentes? Quais os gastos que vou ter nessa nova possibilidade? Carioca se perguntava constantemente: o que devo fazer? Ir atrás dos clientes ou esperar que eles venham até mim? E se acaso isso não ocorrer e as vendas continuarem caindo, o que vou fazer para alcançar a sustentabilidade do meu negócio?

\section{ANÁLISE E DILEMA DO CASO}

Ao longo do caso, Carioca teve que tomar grandes decisões, como mudar de cidade, abandonar sua carreira de locutor, e a principal: constituir sua própria empresa. Ao abrir seu negócio teve que escolher a área de atuação, o local para instalação, o público alvo, definir o preço e a qualidade dos produtos a comercializar, entre outros aspectos relacionados com a gestão do seu negócio. Contudo, apesar de Carioca ter um perfil empreendedor e na sua cabeça ter de forma clara as informações do seu negócio, não avaliou adequadamente as informações necessárias para decidir se o negócio era realmente viável.

Carioca possuía orientação suficiente para analisar a viabilidade da barraca de cachorro quente? Será que Carioca fez a escolha correta ao abrir sua barraca neste local? E como seria se ele estivesse tomando suas decisões baseadas em um plano de negócio? 0 plano de negócios daria ao novo empresário uma visão mais detalhada sobre o ramo de atuação, os produtos, os clientes, contribuindo de forma a visualizar a real viabilidade do negócio? Ao não fazer isso desta forma, Carioca perdeu a oportunidade de conhecer informações importantes do negócio, que poderiam influenciar na avaliação sobre se o seu negócio traria o retorno financeiro que ele esperava ou não?

Carioca neste momento encontra-se em um dilema: sabe que é preciso reposicionar sua empresa no mercado para que passe a ter maior retorno financeiro. No entanto, mesmo possuindo competências empreendedoras como: iniciativa, persistência, criatividade e comprometimento, entre outras, Carioca não calculou de maneira adequada os riscos de suas ações na abertura da barraca de cachorro quente, e os reflexos da falta de planejamento ele está percebendo no retorno financeiro que está alcançando com o seu negócio. E agora? $\mathrm{O}$ quê Carioca deve fazer? Caso decida continuar com seu empreendimento, qual seria a melhor estratégia para alavancar o seu negócio? Como Carioca deve operacionalizar essa estratégia? 


\section{NOTAS DE ENSINO}

\section{Obtenção dos dados}

As informações descritas no texto foram todas coletadas a partir de entrevistas junto ao proprietário da empresa. Trata-se de um caso real. O nome da empresa e dos personagens citados no texto foram alterados para preservar a identidade do caso analisado.

\section{Utilização recomendada}

O caso foi elaborado para aplicação principalmente com alunos de graduação e de pósgraduação do curso de administração e áreas afins, preferencialmente nas disciplinas de empreendedorismo, gestão empresarial, administração estratégica e teoria das organizações. Espera-se que o aluno, por meio do caso, desenvolva um entendimento sobre competências empreendedoras e a importância da estratégia na tomada de decisão no contexto de pequenas empresas, sobre aplicação dos conceitos teóricos na prática administrativa.

\section{Objetivos de Aprendizagem}

O caso de ensino apresenta uma situação em que o gestor de uma pequena empresa deve tomar uma decisão importante. Desta forma, pode-se destacar alguns temas de aprendizagem:

1. Identificar as possibilidades de tomada de decisões no caso e analisar possíveis soluções para o dilema;

2. Discutir os fatores que foram determinantes para a empresa no que diz respeito às competências empreendedoras do gestor;

3. Propiciar reflexões sobre situações que permitam aos alunos analisar conceitos necessários para a tomada de decisão;

4. Debater sobre a realidade enfrentada por pequenas empresas frente às dificuldades financeiras e administrativas.

\section{Sugestão de Plano de Ensino}

Como sugestão para a compreensão e análise do caso pelo professor, para que se possa orientar a discussão em sala de aula, aconselham-se os seguintes passos:

a) Preparação individual com leitura prévia dos alunos;

b) Recomenda-se que o professor disponibilize um período de 30 a 45 minutos para que os alunos discutam o caso em pequenos grupos;

c) Discussão orientada pelo professor com apresentação de cada grupo (1 hora);

d) Fechamento da discussão do caso pelo docente (20 a 30 minutos).

A seguir apresentamos um conjunto de questões que podem ser usadas para estimular a análise do caso durante a etapa de discussão:

1. Com base na teoria sobre competências empreendedoras, quais foram os possíveis erros cometidos por Carioca na abertura da barraca de cachorro quente?

2. Analisando as competências de Carioca, quais seriam as suas sugestões de escolha estratégica com relação ao futuro da barraca de cachorro quente? Arriscar ou tentar 
manter sua barraca onde ela está instalada? Justifique com base nas características do proprietário, apresentadas no caso.

3. Se você estivesse na situação do proprietário da empresa qual seria sua estratégia no caso da mudança da barraca para a compra de um trailler? Como a elaboração de um plano de negócio poderia auxiliar na avaliação de sua escolha estratégica?

\section{TEORIA RECOMENDADA}

Para auxiliar o professor quando da aplicação deste caso, os autores sugerem algumas teorias de suporte, que poderão ser utilizadas durante o processo de discussão e aprendizagem. Neste item serão abordadas teorias relacionadas a empreendedorismo, competências empreendedoras e plano de negócios.

\section{EMPREENDEDORISMO}

O tema empreendedorismo tem sido utilizado e aplicado em inúmeras organizações com fins lucrativos e nos últimos anos verificam-se estudos em instituições governamentais e de ensino com o intuito de melhorias significativas em seus processos de inovação e novas estratégias de negócios. $\mathrm{O}$ empreendedorismo é visto hoje como um os principais propulsores do crescimento econômico, por meio da criação de empregos e renda para a população, melhorando significativamente as condições de vida de uma grande parcela de brasileiros (BRACHT; WERLANG, 2015,). Alguns autores arriscam-se a afirmar que estamos vivendo a era do empreendedorismo (AIDAR, 2007; DORNELAS, 2009).

Para Venkataraman (1997, p. 120), o empreendedorismo é "o campo de estudo que procura compreender como as oportunidades que geram novos produtos e serviços são descobertas, criadas e exploradas, por quem e com que consequências". Filion (1999), evidencia que a chave do empreendedorismo está na percepção e no aproveitamento das novas oportunidades no âmbito dos negócios, ter a visão de enxergar a longo prazo, que pode ser muito lucrativo.

Morrison (1998) sintetiza que, no coração dos empreendimentos, estão os responsáveis empreendedores, persistentes em sua busca de oportunidades de negócios e esforçados em conseguir os recursos necessários para tal viabilidade. O empreendedor de sucesso, ao agregar valor a produtos e serviços, está permanentemente preocupado com a gestão de recursos e com os conceitos de eficiência (BAGGIO; BAGGIO, 2014).

o empreendedor precisa ser capaz de enxergar, de avaliar uma oportunidade e trabalhar para que a mesma se concretize, antes que outro empreendedor tenha a capacidade de visualizar uma fonte de negócio e colocar em prática primeiro. Para Leite (1998, p. 117), empreendedor é "aquele que faz as coisas acontecerem, pois além de ser capaz de identificar oportunidades de mercado, possui uma aguçada sensibilidade financeira e de negócios, para transformar aquela ideia em um fato econômico em seu benefício".

Boava e Macedo (2006, p. 13) definem o empreendedor da seguinte forma: "[...] tratase, portanto, de uma pessoa que transforma sua potencialidade em realidade, abarcando as mais variadas esferas da vida social, tais como: negócios, política, esportes, entre outras".

Nesta mesma linha de conceituação de empreendedor, que é bastante utilizada como referência sobre empreendedorismo, Filion (1999, p. 19) destaca: “o empreendedor é uma pessoa criativa, marcada pela capacidade de estabelecer e atingir objetivos e que mantém alto nível de consciência do ambiente em que vive, usando-a para detectar oportunidades de 
negócios. $\mathrm{O}$ autor salienta ainda que um "empreendedor que continua a aprender a respeito de possíveis oportunidades de negócios e a tomar decisões moderadamente arriscadas que objetivam a inovação, continuará a desempenhar um papel empreendedor".

Segundo Marshall (1985), o empreendedor é uma pessoa que alia os fatores de produção, trabalho e capital para gerar uma maior produção de bens e serviços com aumento proporcional de riqueza e bem-estar material da sociedade como um todo. Drucker (2002) caracteriza os empreendedores como pessoas que inovam. Para o autor, a mudança sempre pode proporcionar a oportunidade para o novo e para o diferente. Em sua visão a inovação sistemática, portanto, consiste na busca deliberada e organizada de mudanças. "O empreendedor é alguém que sonha e busca transformar seu sonho em realidade" (DOLABELA, 2010, p. 25).

Neste sentido, o empreendedorismo está relacionado à inovação, conhecimento e competências empreendedoras. A inovação na visão de Drucker (1987) é o instrumento específico dos empreendedores, é o meio pelo qual eles exploram a mudança como uma oportunidade para um negócio novo que possa surgir, ou um serviço diferente que pode ser criado, [...] levando em consideração a iniciativa empreendedora como veículo ideal para inovar, aumentar a produtividade e melhorar modelos de negócios (DRUCKER, 1987). Deste modo, entende-se que não adianta ser apenas inovador. É necessário se ter o conhecimento suficiente para colocar a ideia em prática e sustentar esta inovação em ambientes competitivos. De acordo com Sarasvathy (2001) em seus estudos sobre empreendedorismo verificou que novos empreendedores percebiam o mundo como dinâmico, instável e incerto. Sendo assim, as atitudes destes estavam orientadas para a experimentação de novos produtos e/ou mercados, busca de parcerias, flexibilidade e disposição para perdas suportadas,

Por sua vez, as habilidades e/ou competências empreendedoras, segundo Mello, Leão e Paiva (2006), está relacionado a capacidade do empreendedor, suas características que o fazem trabalhar na criação e ou inovação de um produto ou serviço e ainda dar continuidade ao projeto.

Logo, pode-se afirmar que os empreendedores estão "eliminando barreiras comerciais, e culturais, encurtando distâncias, globalizando e renovando os conceitos econômicos, criando novas relações de trabalho e novos empregos, quebrando paradigmas e gerando riqueza para a sociedade" (DORNELAS, 2009, p. 6). Desta forma, entende-se que os empreendedores estão cada vez mais ganhando espaço em um mercado bastante competitivo onde as informações circulam de maneira rápida deixando muitas oportunidades a serem exploradas para aqueles que conseguem utilizar de seu conhecimento e de suas competências empreendedoras para alavancar seu negócio.

Neste sentido os empreendedores possuem algumas características. Fillon (1999) cita como por exemplo: a) têm sonhos realistas, ou visões, com cuja realização estão comprometidos; b) gastam tempo imaginando onde querem chegar e como chegar; c) delegam e treinam seus empregados para lidar com o inesperado. Dornelas (2014) formou uma nova relação das características dos empreendedores de sucesso, a qual contempla: ser visionário; saber tomar decisões; fazer a diferença e explorar ao máximo as oportunidades; ser determinado, dinâmico, dedicado, otimista e apaixonado pelo que faz; ser independente e construir seu próprio destino; ficar rico; ser organizado, líder, formador de equipe e bem relacionado; possuir conhecimento; assumir riscos calculados, criar valor para a sociedade e planejar muito. 
Como foi destacado que o empreendedor é aquele que tem visão, que sabe agir e enxergar oportunidades a partir de suas características e competências, essa união de competências individuais com ações empresariais fez emergir, principalmente nos últimos anos, diversos conceitos de competências empreendedoras (ZAMPIER, TAKAHASHI FERNANDES, 2012). Desta forma, cabe-se conhecer mais sobre o tema competências empreendedoras.

\section{COMPETÊNCIAS EMPREENDEDORAS}

O sucesso de muitos empreendedores está relacionado às suas competências, aonde seu conhecimento, capacidades, habilidades e atitudes são bem trabalhadas e definidas no que diz respeito à condução do negócio nas quais atuam (LE BOTERF, 2003; LENZI, 2008; LENZI et al., 2012). Nesta perspectiva, Fleury e Fleury (2004) destaca que a capacidade do indivíduo ter iniciativas, ir além das atividades estabelecidas, ser capaz de compreender e de dominar novas situações de trabalho, ser responsável e ser reconhecido são competências fundamentais para um desempenho organizacional superior.

Lenzi (2008) destaca que assim como um indivíduo lapida suas próprias competências e habilidades, um indivíduo empreendedor pode adaptar suas individualidades a fim de desenvolver uma competência empreendedora. De Oliveira e De Oliveira (2006) destaca que as competências dos dirigentes são tão importantes quanto às estratégias adotadas ou as ações implementadas pela empresa. No campo do empreendedorismo, a definição de competências assume novos sentidos já que tanto as competências individuais quanto práticas administrativas acabam vindo à tona, tornando difícil separá-las (BEHLING; LENZI, 2016).

Pode-se definir que a competência chave de uma empresa é o resultado da combinação das competências dos indivíduos e das competências coletivas, pois "o saber combinatório está no centro de todas as competências" (LE BOTERF, 2003, p. 13). Lizote e Verdinelli (2014), destacam que as competências empreendedoras podem ser compreendidas como um construto que engloba diferentes traços de personalidade, habilidades e conhecimentos.

As competências empreendedoras podem ser caracterizadas como "um saber agir responsável e reconhecido, que implica mobilizar, integrar, transferir conhecimentos, recursos e habilidades, que agreguem valor econômico à organização e valor social ao indivíduo" (FLEURY; FLEURY, 2001, p. 188). Portanto, do ponto de vista da empresa, as competências devem agregar valor econômico, e do ponto de vista individual, elas devem acrescentar valor social às pessoas.

De acordo com Antonello (2005), as competências empreendedoras podem ser compreendidas como um conjunto de conhecimentos, habilidades e atitudes que viabilizam um indivíduo imprimir sua visão, estratégias e ações na criação de valor (tangíveis ou intangíveis) para a sociedade.

Conforme explicam Fleury e Fleury (2006), as competências do empreendedor podem ser divididas em três grandes partes, envolvendo o indivíduo e a empresa como um todo. São estas: (i) competência de negócio: está relacionada à compreensão do negócio, a identificação de oportunidades e de ameaças, e as necessidades ou as exigências do mercado; (ii) competência técnica: envolve o conhecimento técnico relativo à sua área de atuação (conhecimento do produto, processo fabril, etc.); e (iii) competências sociais: são as 
competências necessárias para interagir com as pessoas, como comunicação, negociação e trabalho coletivo.

nos estudos de Man e Lau (2000), os autores dividem as competências em seis áreas distintas do comportamento, são elas: a competência de oportunidade, de relacionamento, conceituais, administrativas, estratégicas e de comprometimento.

- Competência de oportunidade: está relacionada ao reconhecimento de oportunidades de negócios e pode ser dividida em três partes: identificação, avaliação e busca de oportunidade de mercado. "Um empreendedor deve estar apto a identificar os cenários favoráveis aos objetivos organizacionais e atuar sobre as potenciais chances de negócios por meio da sua avaliação de modo a transformá-las em situações positivas" (PAIVA JR., LEÃO MELLO, 2003, p. 2).

- Competência de relacionamento: caracteriza pelo relacionamento com demais indivíduos, relacionamento em rede (networking), sendo primordial para o desenvolvimento profissional, abrange o cotidiano das pessoas, como prática de sobrevivência em um saber fazer relacional (netliving) (MINARELLI, 2001).

- Competências conceituais: diz respeito a visão observadora dos empreendedores, no que se refere a ações inerentes da organização tanto no ambiente interno como no ambiente externo, precisam ser capazes de visualizar situações por ângulos diferentes para encontrar alternativas para tal situação. Quando outros indivíduos estão vendo o mercado saturado, esses empreendedores são capazes de descobrirem nichos para entrar no mercado e se adaptar ao novo ambiente (MAN; LAU, 2000).

- Competências administrativas: a competência administrativa está relacionada à eficiente alocação de talentos, recursos físicos, financeiros e tecnológicos. Esse processo se desdobra em mecanismos de planejamento, organização, comando, motivação, delegação e controle (MAN; LAU, 2000).

- Competências estratégicas: se refere à escolha e implementação de estratégias da organização. Os empreendedores eficientes precisam ser capazes de visualizar situações em longo prazo e se prevenirem para traçar estratégias bem como tomar decisões de curto prazo.

- Competências de comprometimento: as competências de comprometimento por sua vez são as que exigem a habilidade de manter a dedicação do empreendedor ao negócio, principalmente em situações adversas. O empreendedor deve haver a capacidade de recomeçar a atividade empresarial, mesmo após situações de insucesso, ou a disposição de não abandonar o negócio no seu período de crescimento, mesmo na ocorrência de crises setoriais (MAN; LAU, 2000).

Nesta perspectiva, um modelo bastante empregado para identificação de competências empreendedoras é o de Cooley (1990), que lista dez características comportamentais de empreendedores bem-sucedidos a saber: busca de oportunidade e iniciativa; persistência; comprometimento; exigência de qualidade e eficiência; correr riscos calculados; estabelecimento de metas; busca de informações; planejamento e monitoramento sistemáticos; persuasão e rede de contatos; independência e autoconfiança.

\section{PLANO DE NEGÓCIO}

O plano de negócio se constitui como um instrumento formalizado que facilita a implantação das empresas. É indicado para analisar a viabilidade do novo negócio, e deve possibilitar a visão do mercado e as descrições relativas ao novo empreendimento (DORNELAS, 2011). No mesmo sentido, Cunha (2016) argumenta que o plano de negócio 
possibilita uma análise da viabilidade da implantação no negócio, fornecendo informações a respeito do empreendimento futuro e é formado por uma estrutura que permite um melhor entendimento sobre o negócio.

É válido que ressaltar, que após a constituição da empresa no mercado, as micro e as pequenas empresas tem enfrentados problemas para se manterem após os três primeiros anos de vida. Conforme dados do Serviço Brasileiro de Apoio às Micro e Pequenas Empresas SEBRAE (2016), o índice de mortalidade é considerado elevado, estimasse-se que chega a $76 \%$ ou mais, isso significa que a cada cinco novas pequenas empresas constituídas no Brasil, apenas uma sobrevivia após o segundo ano de vida. Essa taxa foi a maior taxa de sobrevivência de empresas com até dois anos, já calculada para as empresas nascidas em todo o período compreendido entre 2008 e 2012 . Esses resultados evidenciam a importância da elaboração de um plano de negócios com projeções para no mínimo próximos cinco anos do seu negócio, para que se possa ter uma noção real se o negócio vai perdurar ou não.

Nascimento (2011) destaca que, apesar da importância das pequenas e microempresas para a economia e para o desenvolvimento regional, é possível identificar elevados índices de mortalidade precoce de micro e pequenas empresas gerados por vários fatores.

O plano de negócios é um documento formulado pelos gestores com o objetivo de planejar um empreendimento ou negócio, em estágio inicial ou não, para que seja possível o delineamento e definição de estratégias organizacionais de atuação para o futuro (DORNELAS, 2011, p.4). Em complemento, Chiavenato e Sapiro (2009, p.128) afirmam que "o plano de negócios é um conjunto de dados e informações sobre o futuro empreendimento, que define suas principais características e condições para proporcionar uma análise da sua viabilidade e dos seus riscos, bem como para facilitar sua implantação".

De acordo com Sahlman (1997), o plano de negócios precisa dispor sobre aspectos fundamentais para o sucesso na empresa, sendo eles:

- As pessoas que irão implantar o negócio e lideram a execução do projeto, ou ainda que vão realizar serviços essenciais no negócio.

- A descrição do negócio, ou seja, o que será comercializado, qual o público alvo a ser atendido, quais os possíveis desafios, qual a estimativa de receita.

- O contexto que envolve o negócio (que não podem ser regulados pelo empreendedor) como normas e regulamentos, leis, taxas de juros, inflação.

- Avaliação dos possíveis ricos e formas de defesa e avaliação das recompensas.

O plano de negócios na visão de Dornelas (2014) é uma ferramenta para o empreendedor testar a viabilidade de seu novo negócio, e não possui uma estrutura fixa, não sendo possível, segundo o autor, estabelecer um modelo padrão, podendo ser adaptado as particularidades de cada empresa. Conforme o autor explica todo plano de negócios deve ser elaborado e utilizado seguindo algumas regras simples, que permitam ao empreendedor utilizar sua criatividade ou o bom senso. No caso das empresas que já se encontram em atividade, ele deve mostrar não apenas aonde a empresa pretende chegar, mas também onde a empresa está no momento, mostrando os valores dos seus atuais indicadores de desempenho.

Porém, afirma Biagio e Batocchio (2005), que o estabelecimento de um plano de negócios deve seguir uma estrutura básica contento uma descrição da empresa, definição de produtos e serviços, análise de mercado, plano de marketing, plano operacional, planejamento financeiro e de investimentos e o planejamento estratégico, todos são 
igualmente importantes, pois estes fatores mostram a capacidade da empresa em "alavancar" os seus resultados financeiros no futuro.

Um plano de negócios bem elaborado possibilita a análise atual e as projeções para o futuro, descrevendo o projeto, o mercado e estabelecendo estratégias, diminuindo os riscos e as incertezas (ROSA, 2007). O plano de negócios apresenta grande importância, pois permite identificar erros que ainda estão no "plano" ou seja, por meio do plano é possível corrigir erros antes de cometê-los no mercado. Dentro de plano de negócios, o planejamento estratégico recebe relevante importância, pois, estabelece ao empreendedor o caminho a ser percorrido para que se alcancem os objetivos propostos (BIAGIO; BATOCCHIO, 2005).

De maneira complementar, conforme explicam Chiavenato e Sapiro (2009) o planejamento estratégico é uma técnica gerencial que oportuniza ao gestor deliberar sobre o rumo da empresa, implicando sobre a necessidade de decisão, que ocorrerá antes, durante e depois da sua elaboração e da sua implantação na empresa. Assim, segundo o autor, o planejamento estratégico é uma ferramenta gerencial que fornece apoio ao processo de tomada de decisão. Essa técnica gerencial auxilia os gestores a terem uma visão dos assuntos de maior relevância na empresa, contribuindo com a obtenção dos resultados esperados.

\section{DESFECHO DO CASO: DA BARRACA DE CACHORRO QUENTE AO “FOOD TRUCK DO CARIOCA”}

Mesmo possuindo características empreendedoras, Carioca precisaria de orientação tanto para implantar estratégias em sua barraca de cachorro quente quanto para inovar com um novo negócio, como sua ideia do Trailler.

Sabendo que precisava reposicionar sua empresa no mercado para que atingisse maior retorno, Carioca um dia estava limpando a frente de sua barraca de cachorro quente, quando recebe a visita das suas clientes e alunas do curso de Administração Bruna e Joana. Elas estavam confiantes que tinham encontrado uma boa solução para a barraca do Carioca.

As acadêmicas apresentaram ao Carioca um plano de negócio para a abertura do "Food Truck do Carioca", plano este elaborado durante uma disciplina do curso como atividade discente. Os pais de Bruna eram proprietários de um terreno em um movimentado local turístico de Florianópolis e estavam dispostos a fazer uma parceria com Carioca, já que o terreno não estava sendo usado. Então Bruna, que já estava se formando no curso, comprou a ideia do Carioca e propôs uma parceria para juntos implantarem essa ideia.

Bruna sugeriu a abertura de um Food Truck e explicou a Carioca que se tratava de uma espécie de cozinha móvel, para vender alimentos, normalmente de forma itinerante, mas como ela possui esse grande terreno, ela apostava na implantação do Food Truck com estacionamento em um local fixo.

Bruna explicou que a infraestrutura necessária para montar um Food Truck precisava ser muito bem planejada para poder atender às necessidades de comercialização dos alimentos. Sugeriu que eles fossem juntos buscar mais informações no Serviço Brasileiro de Apoio às Micro e Pequenas Empresas (SEBRAE). Lá eles receberam as informações que precisavam a respeito das exigências da Agência Nacional de Vigilância Sanitária (ANVISA), Prefeitura e Departamento Estadual de Trânsito (DETRAN), bem como deveriam proceder para obter a concessão da prefeitura e da vigilância sanitária para a implantação do negócio. Com o auxílio do SEBRAE, ainda receberam informações sobre o modelo de negócios para Food Truck, bem como formas de gestão nesse mercado. Essas informações foram fundamentais para a implantação do sonho deles. 
Então Bruna entrou com o Terreno e Carioca teve que fazer um investimento de aproximadamente $\mathrm{R} \$ 60$ mil com a compra do caminhão adaptado para a cozinha e os equipamentos. Para isto, Carioca se desfez de sua casa e comprou outra de menor valor. Assim, viabilizou o reposicionamento do seu negócio e ao mesmo tempo assegurou um local para sua família morar.

Com a formalização da parceria realizada entre Carioca e Bruna, eles conseguiram posicionar-se no mercado atuando de maneira competitiva e de forma organizada. $O$ empreendimento passou a ser bem-sucedido, se transformando de uma simples barraca de cachorro quente ao conhecido e inovador "Food Truck do Carioca". Atualmente Food Truck do Carioca é um sucesso, possui muitos clientes fiéis e recebe um grande número de clientes que vem para conhecer seus produtos e serviços, principalmente em época de temporada de verão, onde triplica o número de visitantes nas praias catarinenses.

Trabalham na empresa atualmente Bruna, Carioca, duas auxiliares de cozinha e ainda Joana, amiga de Bruna, que então formada em administração, cuida de toda parte burocrática da empresa, como rotinas relacionadas ao departamento pessoal, contabilidade, recursos humanos, etc.

Relatando os momentos mais difíceis enfrentados pelos novos sócios neste novo empreendimento, Carioca e Bruna destacam que sentiram muita dificuldade a respeito das legislações que regulamentam a categoria Food Truck, mas conseguiram superar essas dificuldades com perseverança e comprometimento. Bruna destaca que a complementaridade das competências empreendedoras de cada um foi o fator chave para sucesso da criação da empresa, e com sucesso da parceria formada, os empreendedores já idealizam outros sonhos, como montar um "Food Park", ou seja, um estacionamento de Food Trucks em local privado para servir mais variedades gastronômicas.

\section{QUESTÕES ADICIONAIS PARA DISCUSSÃO}

Diante do desfecho apresentado, que decisões e ações foram fundamentais para o sucesso do Food Truck do Carioca?

Quais foram as competências determinantes para abertura do Food Truck do Carioca?

Como a pesquisa de mercado e a análise SWOT poderiam contribuir para uma melhor avaliação quando da abertura do Food Truck?

\section{REFERÊNCIAS}

ANTONELLO, Claudia Simone. A metamorfose da aprendizagem organizacional: uma revisão crítica. Aprendizagem organizacional e competências. Porto Alegre: Bookman, p. 12-33, 2005.

BAGGIO, Adelar Francisco; BAGGIO, Daniel Knebel. Empreendedorismo: Conceitos e definições. Revista de Empreendedorismo, Inovação e Tecnologia, v. 1, n. 1, p. 25-38, 2015.

BATOCCHIO, Antônio; BIAGIO, Luiz Arnaldo. Plano de Negócios-estratégia para micro e pequenas empresa. São Paulo, Manole, 2005. 
BEHLING, Gustavo; LENZI, Fernando César. A relação entre competências empreendedoras e comportamento estratégico: um estudo com microempreendedores individuais (MEI). Encontro de Estudos sobre Empreendedorismo e Gestão de Pequenas Empresas, v. 11, 2016.

BOAVA, Diego Luiz Teixeira; MACEDO, Fernanda Maria Felício. Estudo sobre a essência do empreendedorismo. Anais do Encontro da Associação Nacional de Pós-Graduação e Pesquisa em Administração, Salvador, BA, Brasil, v. 30, 2006.

BRACHT, Danieli Eidt; WERLANG, Nathalia Berger. Competências empreendedoras: uma investigação com produtores rurais catarinenses. REGEPE-Revista de Empreendedorismo e Gestão de Pequenas Empresas, v. 4, n. 1, p. 101-124, 2015.

CHIAVEnAtO, I.; SAPIRO, A. Planejamento estratégico. 4 ed. Rio de Janeiro: Elsevier, 2009.

COOLEY, Lawrence. Entrepreneurship training and the strengthening of entrepreneurial performance. Final Report. Contract. Washington: USAID, 1990.

CUNHA, Homero Silva Canabarro. Plano de negócio: implantação de uma prestadora de serviços comercial e logística para microcervejarias. São Paulo: Atlas, 2016.

DA COSTA, Alessandra Mello; BARROS, Denise Franca; CARVALHO, José Luis Felicio. A dimensão histórica dos discursos acerca do empreendedor e do empreendedorismo. Revista de Administração Contemporânea, v. 15, n. 2, p. 179-197, 2011.

DE OLIVEIRA, Dilson Campos; DE OLIVEIRA GUIMARÃES, Liliane. Perfil empreendedor e ações de apoio ao empreendedorismo: o NAE/SEBRAE em questão. Revista Economia \& Gestão, v. 6, n. 13, 2006.

DOLABELA, Fernando. A corda e o sonho. Revista HSM Management, v. 80, p. 128-132, 2010.

DORNELAS, José Carlos Assis. Empreendedorismo: transformando ideias em oportunidades. São Paulo, Atlas, 2014.

DORNELAS, José Carlos Assis. Plano de negócios: seu guia definitivo. Rio de Janeiro: Campus, 2011.

DORNELAS, Jose Carlos Assis. Empreendedorismo corporativo. Elsevier Brasil, 2009.

DRUCKER, Inovação e espírito empreendedor - entrepreneurship: prática e princípios. São Paulo: Pioneira Thomson, 2002.

DRUCKER, Peter F. Inovação e espírito empreendedor: prática e princípios. São Paulo: Pioneira, 2002.

DRUKER, Peter F. Inovação e espírito empreendedor (entrepreneurship): prática e princípios. São Paulo: Pioneira, 1987. 
FILION, Louis Jacques. Empreendedorismo: empreendedores e proprietários-gerentes de pequenos negócios. Revista de Administração, v. 34, n. 2, p. 5-28, 1999.

FLEURY, Afonso; FLEURY, Maria Tereza Leme. Estratégias empresariais e formação de competências: um quebra-cabeça caleidoscópio da indústria brasileira. São Paulo: Atlas, 2004.

FLEURY, Maria Tereza Leme; FLEURY, Afonso. Construindo o conceito de competência. Revista de Administração Contemporânea, v. 5, n. SPE, p. 183-196, 2001.

HISRICH, Robert. PETERS.; Michael P. Empreendedorismo. São Paulo: Atlas, 2004.

LE BOTERF, Guy. Desenvolvendo a competência dos profissionais. São Paulo: Artmed, 2003.

LEITE, Roberto C. De executivo a empresário: como realizar o seu ideal de segurança e independência. Rio de Janeiro: Campus, 1998.

LENZI, Fernando Cesar. Os empreendedores corporativos nas empresas de grande porte dos setores mecânico, metalúrgico e de material elétrico/comunicação em Santa Catarina: um estudo da associação entre tipos psicológicos e competências empreendedoras reconhecidas. 2008. Tese de Doutorado. Universidade de São Paulo.

LIZOTE, Suzete Antonieta; VERDINELLI, Miguel Angel. Competências empreendedoras: um estudo com funcionários administrativos de uma empresa do ramo alimentício. Revista Pensamento Contemporâneo em Administração, v. 8, n. 1, 2014.

MAN, Thomas WY; LAU, Theresa. Entrepreneurial competencies of SME owner/managers in the Hong Kong services sector: A qualitative analysis. Journal of Enterprising Culture, v. 8, n. 03, p. 235-254, 2000.

MARSHALL, Alfred. Princípios de economia: tratado introdutório. São Paulo, Manole, 1985.

MELLO, Sérgio Carvalho Benício de; LEÃO, André Luiz Maranhão de Souza; PAIVA JÚNIOR, Fernando Gomes de. Competências empreendedoras de dirigentes de empresas brasileiras de médio e grande porte que atuam em serviços da nova economia. Revista de Administração Contemporânea, v. 10, n. 4, p. 47-69, 2006.

MINARELLI, José Augusto. Networking: como utilizar a rede de relacionamentos na sua vida e na sua carreira. Editora Gente Liv e Edit Ltd, 2001.

MORRISON, Alison J. (Ed.). Entrepreneurship: An international perspective. Routledge, 1998.

NASCIMENTO, Marcelo; LIMA, Carlos Rogério Montenegro de; LIMA, Mauricio Andrade de; ENSSLIN, Eduardo Rolim. Fatores determinantes da mortalidade de micro e pequenas empresas da região metropolitana de Florianópolis sob a ótica do contador. Revista Eletrônica Estratégia \& Negócios, Florianópolis, v. 6, n. 2, p. 244-283, mai./ago. 2013.

ROSA, Claudio Afrânio. Como elaborar um plano de negócio. Brasília: SEBRAE, 2007. 
SAHLMAN, William A. How to write a great business plan. Harvard Business Review, v. 75, n. 4, p. 98-109, 1997.

SARASVATHY, Saras D. Causation and effectuation: Toward a theoretical shift from economic inevitability to entrepreneurial contingency. Academy of Management Review, v. 26, n. 2, p. 243-263, 2001.

SEBRAE - Serviço Brasileiro de Apoio às Micro e Pequenas Empresas. Disponível em: <http://www.sebrae.com.br>. Acesso em: 28 de maio de 2018.

SEBRAE. Serviço Brasileiro de Apoio às Micro e Pequenas Empresas. Fatores condicionantes e taxa de mortalidade de empresas. Relatório de pesquisa. Brasília, 2004.

SEBRAE. Serviço Brasileiro de Apoio às Micro e Pequenas Empresas. Sobrevivência das empresas no Brasil. Relatório de pesquisa. Brasília, 2016.

VENKATRAMAN, Sankaran. The distinctive domain of entrepreneurship research. Advances in Entrepreneurship, Firm Emergence and Growth, v. 3, n. 1, p. 119-138, 1997.

ZAMPIER, Márcia Aparecida; TAKAHASHI, Adriana Roseli Wunsch; FERNANDES, Bruno Henrique. Sedimentando as bases de um conceito: As competências empreendedoras. REGEPE-Revista de Empreendedorismo e Gestão de Pequenas Empresas, v. 1, n. 1, p. 101-130, 2012. 